\title{
Pedagogical continuity: myth or reality?
}

\author{
Lalina Coulange, Kari Stunell and Grégory Train \\ University of Bordeaux, Bordeaux, France
}

\begin{abstract}
Purpose - In March 2020, with only two working days'notice the French national education system went online due to the coronavirus pandemic. This study explores the relationship between the move to distance learning, the teaching practices employed and the socio-economic context of the learners in French schools during this period. We ask how far the changes in teaching practices during the coronavirus crisis were influenced by the social context of teaching. And to what extent this context influenced the focus of the pedagogical continuity those teachers set up.

Design/methodology/approach - A review of the literature situates the study within the field of mathematics teaching practices. The study was carried out through a multidimensional analysis using multiple correspondences of the responses of 368 French secondary school mathematics teachers to an online questionnaire.

Findings - We found that the unprepared move to distance learning impeded the employment of dialogic practices. The socio-economic situation of the teaching was identified as a determining factor in the teachers' different interpretations of the term pedagogical continuity. Whilst those working in more deprived areas tended towards practices which focused on maintaining pupils' links with school, consolidation of knowledge and providing social/affective support, those teaching a more privileged public favoured tools and practices which allowed them to focus on the disciplinary content of their teaching.

Practical implications - The challenge of maintaining dialogic activities - teacher education to combat inequalities.
\end{abstract}

Originality/value - A quantitative study of mathematics teachers providing pedagogical continuity through distance learning for the duration of the crisis.

Keywords Pedagogical continuity, Teacher practices, Distance learning, Educational inequality, Parental involvement in learning

Paper type Research paper

\section{Introduction}

As a result of the coronavirus pandemic, on Tuesday 17th March 2020 French schools were closed and teachers were directed to assure pedagogical continuity through distance learning for the duration of the crisis. The situation was unprecedented. The announcement came on the evening of the 12th March, leaving teachers just two in-school working days to prepare; one in the presence of the pupils and one without them. At the time of writing (end of May 2020 ), after an initial period of full closure that lasted for eight weeks, only $22 \%$ of France's $12 \mathrm{~m}$ school children are back in the classroom.

The French school system is traditionally highly centralised. Its philosophical roots go back to Jules Ferry's education reforms $(1881,1882)$ in which free, compulsory education for all were imposed as a means of building equality and social justice. The government, through the Education Ministry, provides a detailed national curriculum and defines the pedagogical approaches to be adopted. However, the pedagogical continuity which teachers were asked to provide from their homes was not clearly defined. In this situation of national crisis, it was left

(C) Lalina Coulange, Kari Stunell and Grégory Train. Published in Journal of Research in Innovative Teaching \& Learning. Published by Emerald Publishing Limited. This article is published under the Creative Commons Attribution (CC BY 4.0) licence. Anyone may reproduce, distribute, translate and create derivative works of this article (for both commercial and non-commercial purposes), subject to full attribution to the original publication and authors. The full terms of this licence may be seen at http:// creativecommons.org/licences/by/4.0/legalcode

Received 30 November 2020 Revised 6 January 2021 Accepted 6 January 2021

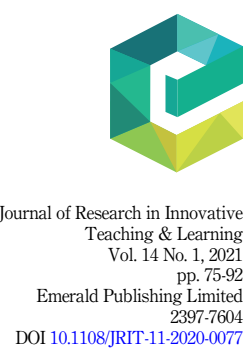


JRIT

14,1

to head teachers and individual staff members to decide how to interpret the term pedagogical continuity and how best to implement it. This situation raises a number of questions concerning teaching practices, online learning tools and equality of educational provision. What digital tools did teachers and pupils have at their disposal? And how could they best be employed to maintain a quality learning environment for all? Could patterns of pupil-teacher interaction developed in the classroom be transposed to the online context? What kinds of tasks could be assigned once each pupil was physically isolated from the others? With the habitual patterns of social interaction so radically changed, how were teachers to maintain interest in learning? And how would the implementation of these different ways of teaching and learning interact with the wider issues of equality and social justice? Furthermore, how would individual teachers interpret the term "pedagogical continuity"? Which aspects of their everyday teaching practices would they seek to maintain and why?

The current article focuses on French secondary school maths teachers in France, 368 of whom completed an online questionnaire about their experiences between the 2 nd and the 5 th week of distance teaching. Through a multidimensional analysis using multiple correspondences analysis, the relationship between the sudden move into distance learning, teacher practices and the socio-economic context of the learners is explored. We ask how maths teachers adapted their role during the period of teaching from home, what factors influenced their choices and how these choices impacted the content taught and the equality of provision. At the time of writing, it is too soon to analyse the full effects of this unplanned period of distance education on teacher development and pupil achievement. Nonetheless, certain lessons can already be learned which open up interesting perspectives in terms of teacher education by providing insights into the co-construction of educational inequalities and the challenges of maintaining dialogic approaches to teaching mathematics within a distance learning format.

\section{Theoretical framework}

\section{Constructivism, socio-constructivism and dialogue in mathematics teaching}

Constructivist and socio-constructivist approaches to mathematical learning have influenced mathematics teaching (Simon, 1995). Introducing new knowledge as a tool for mathematical problem solving has its origins in constructivist approaches (Glaeserfeld, 1991; Brousseau, 2002; Steffe, 1991). From socio-constructivism comes the view that dialogue and communication are essential to the learning process (Cobb and Bauersfield, 1995; Krummheuer, 1988; Voigt, 1994). For the socio-constructivists, mathematical knowledge is socially originated and mathematical debate synonymous with doing mathematics and developing meaning. From this perspective, "participating in mathematical communication is learning mathematics" (Planas et al., 2018, p. 117). As Stamou and Chronarki (2007) remark, students need to be helped to move away from a vision of mathematical knowledge as established by an external authority, towards a vision of mathematical knowledge as something they can construct for themselves through their own activity.

However, implementing this in the classroom has proved challenging (Simon, 1995; Cohen, 1998; Gordon, 2009; Windschitl, 2002). Introducing new knowledge through problem-solving activities engenders more complex classroom organisation than more traditional transmissive methods of introducing knowledge. Rather than setting simple tasks which can be carried out in isolation, the teacher needs to engage students in complex thinking which gives them a role in the co-construction of knowledge. Reflection about the kinds of activities which create such opportunities has led to the development of new models and methods for maths teaching. Manipulating objects to create links between empirical realities and abstract concepts (Planas et al., 2018), discovery approaches (Stamou 
and Chronarki, 2007) and non-routine problems (Simon, 1995) have all been used with interesting results.

Giving dialogue a key role in learning (Pimm, 2004) challenges the traditional organisation of classroom interactions. These can take a number of forms (between individuals, within small groups, involving the whole class) and can be planned (as in the introductory or restitution phases) or spontaneous (as when a teacher acts to facilitate learning or responds to a student's question). Within these different contexts, teacher-student interactions can serve a number of different purposes (procedural, constructive, de-contextualising, recontextualising, questioning). For classroom interactions to help students to create and transform knowledge, the teacher must lead the pupils towards their "own" discovery of what is nonetheless required knowledge, via a careful process of observation of student activity, listening, questioning and responding (Barwell, 2016; Planas et al., 2018).

\section{Teaching mathematics in the ordinary high school classroom}

Within an ordinary high school mathematics classroom a number of contextual features also influence teacher choices and actions. The plurality of factors which interact to influence pedagogical decision-making has been studied, both within situations of teacher innovation (Salomon, 1990; Kennewell et al., 2000; Fullan, 2001; Kozma, 2003) and in terms of ordinary practices (Robert, 2001; Robert and Rogalski, 2002). In this study, we use the theory of activity (Robert and Rogalski, 2002; Robert and Hache, 2013) which posits five such components; the personal, the institutional, the social, the cognitive and the mediatory. The personal component describes the attitudes, beliefs and representations, derived from personal, educational and professional experiences of teaching, which influence a teacher's vision of his or her role. This role is played out within an institutional arena where factors such as the curricula, the schedule, standardised testing practices and the material in the classroom frame teacher actions. Teacher practices are also socially situated and must take into account the needs, expectations and circumstances of a variety of other actors including pupils, colleagues, parents, administrators and inspectors. Robert and Rogalski (2002) regroup these three components in a class of professional factors which provide the framework within which teachers make choices related to task type, content and organisation (the cognitive component) and classroom interactions (the mediatory component). In practice, the cognitive and mediatory components interact on many levels. The challenge of designing activities which provide for the introduction of knowledge through problem-solving relates to the cognitive component. However, the success of these activities as opportunities for knowledge construction depends to a large extent on the teacher-to-pupil and pupil-to-pupil interactions involved in setting up, carrying out, monitoring and giving feedback on the activities. These dialogic elements of the classroom activity relate to the mediatory component. This component interacts with the cognitive component by helping students to link specific tasks or activities with more general theoretical notions. As Adler (2001), Barwell and Pimm (2016), note, pupil access to learning depends to a large extent on the mediatory component of a teacher's practice.

\section{Context of the present study}

Taking mathematics teaching on line

The challenges of introducing new knowledge through problem-solving activities and of giving dialogue a central role in the learning process are potentially amplified by taking teaching online. Moving from a presential to a distance learning format calls for reorganisation of both the cognitive and mediatory components of teacher activity. Once pupils and the teacher are no longer in the same physical space, the nature of classroom

Pedagogical continuity 
JRIT

14,1

78

communication is radically changed. The new situation requires the teacher to adapt the mediatory component, the tool through which classroom interactions are regulated. However, Chappet-Pariès et al. $(2008,2013)$ note that the mediatory component of a teacher's activity tends to become stabilised relatively early in their career. Teachers innovate within the cognitive component of their practice, by exploring new activities, whilst the mediatory component provides a constant in their practice. From this point of view, suddenly moving teaching online is likely to be challenging. Furthermore, since the mediatory and cognitive components of teaching are so closely interrelated, changes to one are likely to require adaptations of the other (Robert, 2001; Robert and Roglaski, 2002).

\section{The institutional and personnel components}

Within the context of the coronavirus pandemic, for teachers working in the national education system in France, the relative weight of the institutional and personal components of teaching shifted. The institutional framework suddenly changed; schools closed and teaching went online in order to maintain pedagogical continuity. Neither the tools to be used in the process of delivering pedagogical continuity, nor the exact meaning of the term were well-defined. For individual teachers, this emphasised the role of the personal and social components in defining their choices about what and how to teach.

\section{The social component}

"Although schools typically embrace an egalitarian ethos and rarely create categories with the goal of producing inequality, many of the most persistent inequalities in contemporary societies originate in schools." (Thurston et al., 2017, p. 315). Despite the importance of the concept of equality within the French system of values, a lack of equality within the French school system has been highlighted in a number of reports (Mullis and Martin, 2016; OCDE, 2019). According to PISA, 2018 France is one of the OECD countries with the strongest correlation between socio-economic status and academic performance in PISA tests. In France, schools officially identified as being in priority education zones due to their socially deprived catchment areas are designated REP schools (Réseaux d'Educative Prioritaire priority education network). In September 2019, 1094 out of 5,300 high schools were thus classified. A 2015-2016 report [1] shows a higher proportion of newly qualified teachers working in REP schools than in non-REP schools.

The relationship between social inequalities and learning is explored in the literature. Studies examine the interactions between teachers, pupils and social context which can serve to fashion and sustain the inequalities within the system (Charlot et al., 1992; Bautier, 2006; Bautier and Rochex, 1998). Pupils view schools through the prism of their own socio-cultural conditioning. Representations of school and schooling derived from parental attitudes and social and family environment are all identified as factors which can inform pupil achievement, teacher expectations, lesson content and conceptualisations of knowledge. Because of the centralised nature of the system, French public high schools are both institutions of academic learning and institutions which embody a wider set of cultural values and a specific culture of learning. However, for a certain percentage of pupils this culture of learning, and the language used to express it are relatively opaque. This makes accessing knowledge more difficult for these pupils and contributes to the inequality in the system.

\section{Mathematics teaching in French high schools}

French high school maths teachers are used to the cognitive and mediatory components of their teaching being guided by a precise curriculum accompanied by institutionally approved teaching materials in the form of textbooks, worksheets and online resources. These 
published materials usually advocate organising lessons in three phases. The influence of constructivist and socio-constructivist approaches can be identified in the first of the phases proposed which typically involves pupils in a dialogic problem-solving activity through which new knowledge can be discovered. Next, students' activity is discussed and the new knowledge is formalised by the teacher through presentation of key vocabulary, definitions and examples. In the third phase, the pupils complete exercises which involve manipulation of the knowledge introduced. Since the 1990s, non-routine problems, problem-solving and tasks which require pupils to show initiative and imagination, to think freely and hypothesise, rather than to listen and memorise routinely appear in most textbooks. (Chevallard, 1999; Hersant and Perrin, 2005).

The average maths teacher in a French high school is responsible for three or four different classes of between 20 and 30 pupils aged from 11 to 15 . Each class receives between $3 \mathrm{~h} 30$ and $4 \mathrm{~h} 30 \mathrm{~h}$ of instruction per week. Teachers typically set homework every lesson which is corrected during class time. This in-class correction time can provide an important opportunity for knowledge construction through dialogue as class discussion of student errors, methods and strategies can be used to help students to generalise concepts from specific situations. Most teachers only collect homework every two or three weeks. High school mathematics teachers are typically familiar with a number of digital learning tools, for example Geogebra, Scratch, tableur, as the national curriculum advocates their use. The only digital tool commonly used outside the classroom is "pronote" which is used to communicate with pupils and parents. Its use is generally limited to sharing information about the timetable, homework and evaluations.

\section{Research questions}

In this article, through an exploration of the interaction between the distance learning tools used during the coronavirus crisis, the teaching practices employed and the socio-economic context of teaching, we look at the different ways in which teachers interpreted the term pedagogical continuity. We ask how far the changes in teaching practices during the coronavirus crisis were influenced by the social context of teaching. And to what extent this context influenced the focus of the pedagogical continuity those teachers set up.

\section{Research design and methodology}

\section{Design}

A descriptive mixed-methods design was used for this quantitative study. Data were collected through a 65-questions online questionnaire. The questions concerned different aspects of teacher practices during the coronavirus pandemic. The majority of the questions (40) dealt with the nature of the distance learning protocol set up by the teachers. They focussed on the cognitive and mediatory components of the teachers' practices asking teachers to describe the adaptations made to their regular teaching practices. The remaining 25 questions focussed on the social, personal and institutional components of the teachers' practices. The information gathered thus comes from teachers' declarations about their practices rather than from direct observation of these practices. Therefore, in order for the corpus to be as objective as possible the majority of the closed format questions asked only for factual information. Several open questions were added in order to allow the teachers to explain and elaborate on their answers (Creswell and Plano-Clark, 2007; Elliot, 2005; Tashakkori and Teddlie, 2003).

\section{Data collection and instrumentation}

The questionnaire was administered to high school mathematics teachers during weeks $2-5$ of the lockdown in March/April 2020. There were 368 responses. The majority of the 
JRIT

14,1

participants were experienced teachers (more than $70 \%$ had more than 6 years teaching experience). However, of the $20 \%$ of teachers working in schools in deprived areas, $40 \%$ had less than six years of experience. $82 \%$ of the participants declared themselves confident using digital technology. These proportions are representative of the general population of French high school mathematics teachers. The principal statistical treatment involved a multidimensional analysis using multiple correspondences (MCA) (Lê et al., 2008; Kostov et al., 2013). The MCA was carried out on the complete dataset. Only those variables dealing with the online teaching protocol were considered active in the analysis. The variables linked to the teaching context were considered supplementary and did not participate in the construction of the factorial axes. This choice allowed us to study the characteristics of teacher practices related to the cognitive and mediatory components of teaching and then to explore the extent to which these characteristics were determined by the social, personal and institutional components inherent in the situation. Examination of the values associated with the different dimensions of the MCA (see Table 1) led to the decision to restrict the analysis to the first six dimensions.

The MCA was completed with a hierarchical analysis (Husson et al., 2010) which allowed for a more intuitive examination of the relationship between individuals. For the classification of the individuals, the first 14 axes were taken into account (representing $38.58 \%$ of the inertia). The others were judged to be noise which would destabilise the clustering.

\section{Results}

Teacher experiences of distance teaching

Despite the lack of preparation, teachers' views of the experience of moving to distance learning were not entirely negative. Half of them found the experience less difficult than they had imagined, and $77 \%$ found it enriching. $48 \%$ state that as a result they intend to incorporate new practices into their ordinary teaching and $73 \%$ that they plan to use new teaching tools when they return to the classroom. $90 \%$ of those who found the experience enriching intend to make changes to their regular practices. On the other hand, $89 \%$ of the respondents stated that the distance learning protocol created educational inequality, and $82 \%$ said that these conditions made it impossible to complete the curriculum. The majority of the respondents $(67 \%)$ thought that distance teaching was more time-consuming than regular teaching.

\section{Global trends in teaching practices}

In total, $64 \%$ of teachers stated that they had changed their practices during this crisis period. A number of trends related to the cognitive and mediatory components of teacher practices can be identified. Firstly, there is a tendency to focus on revision exercises to the detriment of the introduction of new knowledge through problem-solving activities and

\begin{tabular}{lccc}
\hline & Eigenvalue & \% of variance & Cumulative \% of variance \\
\hline Dim 1 & 0.11708 & 4.617 & 4.617 \\
Dim 2 & 0.10029 & 3.955 & 8.572 \\
Dim 3 & 0.08630 & 3.408 & 11.976 \\
Dim 4 & 0.07516 & 2.964 & 14.940 \\
Dim 5 & 0.06794 & 2.679 & 17.620 \\
Dim 6 & 0.066919 & 2.639 & 20.259 \\
\hline
\end{tabular}

Table 1.

Eigenvalues associated with the first six dimensions of the MCA Dim 6 
tasks. $79 \%$ of the $64 \%$ of respondents who report changing their teaching practices during this period say that these changes include not tackling new concepts. Although $30 \%$ of the teachers report changes which involved giving more time to the introduction of new notions, this time tended to be used for transmissive knowledge presentation rather than dialogic discovery activities. Secondly, there is a tendency for teachers to ask pupils to hand in more written homework for teacher correction than would be usual in ordinary classes. Study of the four distinct teacher profiles produced by the hierarchical analysis allows a more in-depth view of how and why teachers adapted their practices during the coronavirus crisis (see Figure 1).

\section{Profiles of teacher practices}

\section{Profile 1}

The first group represents $14.6 \%$ of the teachers. The cognitive component of these teachers' practice remained relatively stable; $66 \%$ of them report no change in the variety of activities proposed. Although $52 \%$ claim to continue to consider the presentation of new notions important, they also report that $25 \%-50 \%$ of their teaching time is spent on formalised knowledge presentation by the teacher. It thus seems likely that it was relatively easy to continue to introduce new knowledge within the distance learning format since coconstruction of knowledge by the pupils does not have a big place in their ordinary practices.
Pedagogical continuity

\section{Factor map}

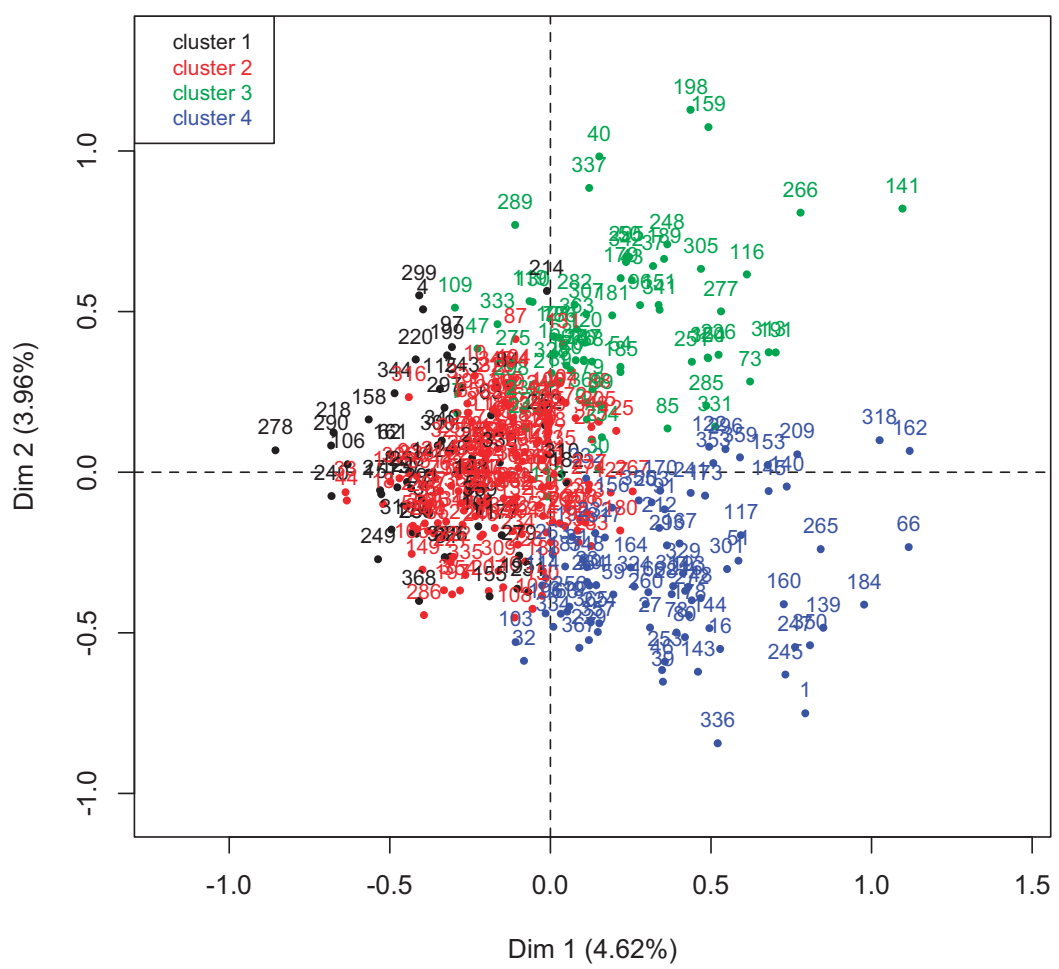

Figure 1. Factorial map individuals are coloured according to the cluster they belong to 
JRIT

14,1

82
The mediatory component of these teachers' practice was also less impacted by going online than is the case for the teachers associated with the other profiles (see Figure 2).

A high level of pupil investment in learning is noted; $96 \%$ of the total cohort of teachers who claim to have a high proportion of pupils strongly invested in learning are in this group. Of those who have used virtual classes, $28 \%$ note a high level of pupil participation (against $14 \%$ across the total cohort). This probably relates to the conditions of at-home study of the pupils which $31 \%$ of the teachers esteem to be of high quality. Parent implication in pupil learning is considered highly satisfactory by $77 \%$ of teachers. Here the social component has a strong positive influence on pedagogical practices. The high level of pupil engagement and parental implication in the learning, combined with the favourable conditions of at-home study allow the teachers to maintain their ordinary practices despite the sudden move to distance learning. This can be linked to the situation of the schools; $31 \%$ of these teachers state that their pupils come from socio-economically privileged backgrounds (as opposed to $18 \%$ of the total cohort) (see Table 2 ).

\section{Profile 2}

This group encompasses $45 \%$ of the respondents making it the biggest cluster formed. Overall, these teachers were keen to continue to propose a variety of activity types, employing activities to introduce new knowledge and discovery activities as well as revision exercises. For the majority, moving to distance learning triggered an evolution in the cognitive component of their practice; the variety of activities which they proposed changed. Generally,

\section{Hierarchical clustering on the factor map}

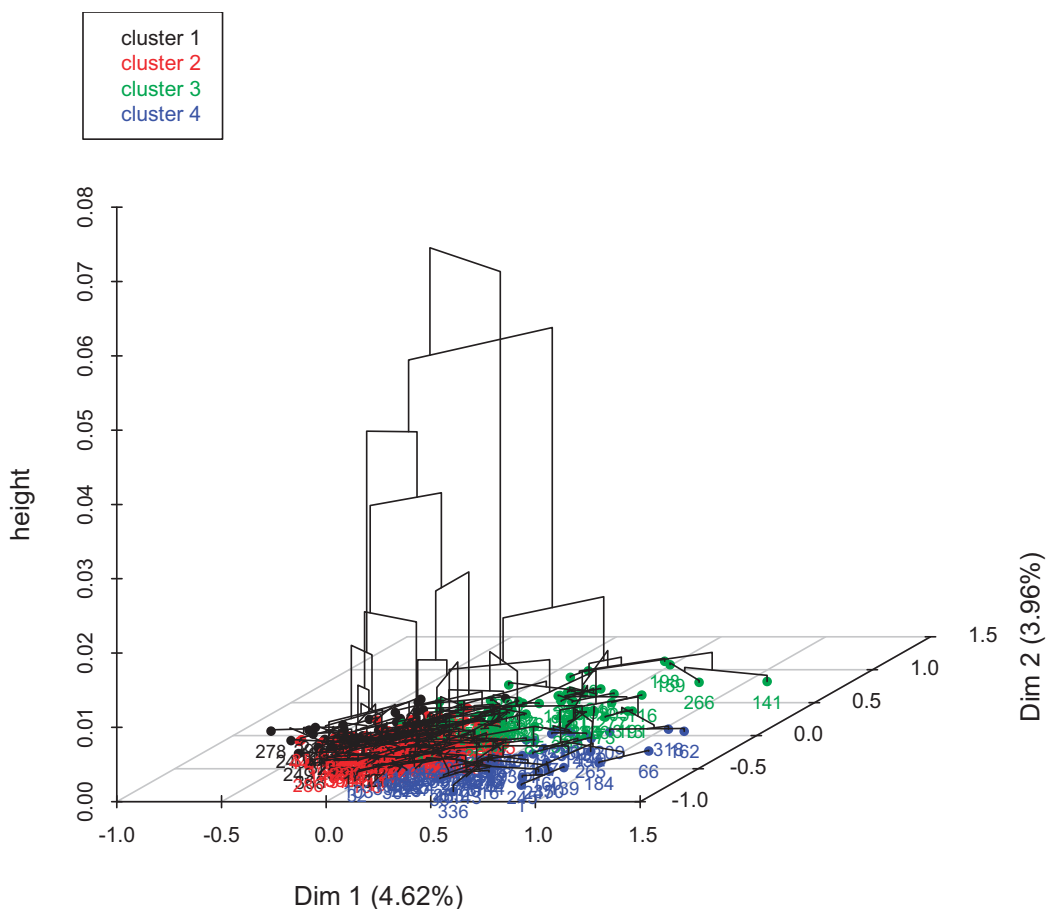

$\operatorname{Dim} 1(4.62 \%)$
Figure 2.

Hierarchical clusteringindividuals are coloured depending on the cluster they belong to 


\begin{tabular}{|c|c|c|c|c|c|c|}
\hline$\ldots$ & Cla/Mod & $\mathrm{Mod} / \mathrm{Cla}$ & Global & $p$.value & $v$.test & $\frac{a}{\mathrm{~V}}$ \\
\hline Revision3 & 65.30 & 46.37 & 13.27 & 0.000000000000003472053 & 7.872651 & \\
\hline Tresinvesti0 & 58.18 & 46.37 & 14.90 & 0.000000000000498822862 & 7.225619 & \\
\hline Investi0 & 69.69 & 33.3 & 8.94 & 0.000000000141220798330 & 6.7566 & \\
\hline Nouveau0 & 46.15 & 52.17 & 21.13 & 0.000000000117393107247 & 6.756661 & \\
\hline Propvirtuel1 & 33.56 & 71.01 & 39.56 & 0.000000005295275770965 & 6.442666 & \\
\hline Condprackwork0 & 54.76 & 33.3 & 11.38 & 0.000000020175689947294 & 5.837617 & 83 \\
\hline Noninvesti3 & 69.56 & 23.18 & 6.23 & 0.000000042365676029248 & 5.610488 & \\
\hline Exputtoprog3 & 32.43 & 69.46 & 40.10 & 0.000000048305138014952 & 5.480696 & \\
\hline Peuinvesti3 & 48.64 & 26.087 & 10.02 & 0.000012256874805436431 & 5.457439 & \\
\hline Rep1 & 39.34 & 34.78 & 16.52 & 0.000030794981366893873 & 4.372968 & \\
\hline Rep0 & $\dddot{14.61}$ & 65.21 & 83.46 & 0.000030794981366893907 & -4.167506 & \\
\hline Revision1 & 9.94 & 26.08 & 49.05 & 0.000019978242281717994 & -4.265134 & \\
\hline Condprackwork2 & 10.10 & 27.53 & 50.94 & 0.000014843716450482168 & -4.330995 & Table 2. \\
\hline Propvirtuel2 & 5.96 & 13.04 & 40.92 & 0.000000042733077199660 & -5.479168 & example of the \\
\hline Condwork2 & 8.20 & 23.18 & 52.84 & 0.000000034987886384812 & -5.514447 & description by \\
\hline Noninvesti0 & 7.52 & 20.28 & 50.40 & 0.000000016812095298893 & -5.641964 & categories (cluster 3) \\
\hline
\end{tabular}

this was viewed positively; $85 \%$ announced that they intend to continue to use new tools explored during the crisis once they return to regular teaching, and $53 \%$ envisage employing new teaching practices. However 38\% report setting a higher proportion of revision exercises. Teacher responses to the open question highlight the challenges implicit in proposing more dialogic work; "more revision (through ritualised exercises ... ) and less research activities (because monitoring them and correcting them is difficult)", "more revision and less discovery activities because I feel less able to help the weaker students" [2]. The comments reveal a tension between teacher desire to maintain normal classroom activities and interactions and the challenges that this presents within a distance learning protocol. The destabilisation of the mediatory component has left them feeling that they have lost access to their habitual mechanisms for managing certain kinds of activity effectively. The results suggest that the social component also had a role to play. Whilst $54 \%$ of the teachers remark that half of their pupils attend virtual classes and are generally engaged with the distance learning protocol, $41 \%$ of them mention that $20 \%-30 \%$ of their pupils demonstrate little investment in the learning. However, $82 \%$ of these teachers report that certain students, who do not usually participate in classes, are highly invested online (see Figure 3).

\section{Profile 3}

This group represents $19 \%$ of respondents. Here, the evolution of the cognitive component is even more pronounced than for the profile 2 teachers. For $74 \%$ the relative importance given to different types of activity during the period of distance learning represents a change in their practice. $47 \%$ now spend more than $75 \%$ of teaching time on revision exercises, and for more than half of them, less than $25 \%$ of the teaching time is dedicated to the introduction of new concepts. Their responses to the open questions highlight their difficulties; "I've no idea how to organise activities which introduce new ideas through distance learning", "with distance learning very few notions are easy to introduce, so lots of reinforcing learning with exercises", "without exchanges or visual monitoring, the introductions are harder". The interaction between the cognitive and mediatory components is clear; the loss of familiar interactive patterns leaves the teachers feeling unable to introduce new knowledge effectively. The characteristics of the social component seem to be at the root of these changes. For $47 \%$ of teachers, less than $20 \%$ of their pupils are engaged in the learning. Of 


\section{JRIT 14,1}

\section{4}

Figure 3.

Graph of the categories in the first factorial level

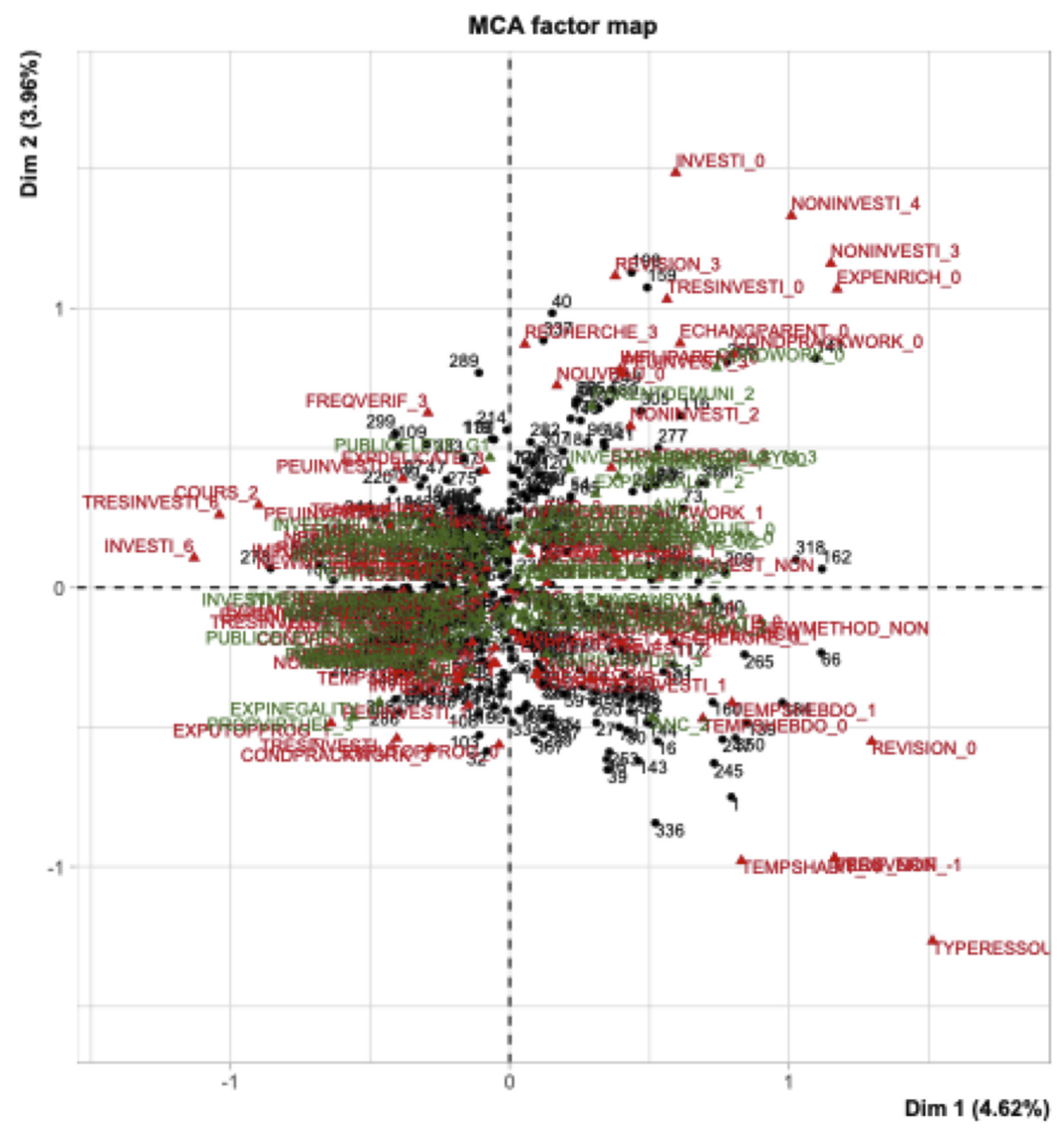

those who use the virtual classroom, $71 \%$ state that more than half of the pupils do not attend. Nevertheless, in general, the teachers remain invested in their work and aim to counterbalance these difficulties through the individualisation of teacher-pupil contact. $96 \%$ of them monitor student work, with $47 \%$ collecting more than two pieces of work a week (compared to $28 \%$ across the whole cohort). For these teachers, the social component has a strong negative influence on their pedagogical choices, rendering teacher-pupil communication difficult and thus ruling out the possibility of maintaining the balance of activities proposed in the ordinary classroom. The majority of teachers working in deprived areas are in this group with 35\% working in REP schools. 32\% describe the home conditions of their pupils as unfavourable to working (as opposed to 11\% across to the whole cohort), and half of them say that the parents are not in a position to adequately help their children with their distance learning work.

\section{Profile 4}

This profile regroups 80 teachers; $21 \%$ of the total cohort. These teachers appear to be less actively engaged with the cognitive component of their practice than those associated with the other profiles. Of the $3 \%$ of the respondents who use only readymade materials $84 \%$ are 
in this group. These teachers show little inclination to view this period of working online as an opportunity to explore the evolution of their practice. This can be to some extent explained by the weight of the personal component in determining their teaching activities. Although the responses do not all focus on the same type of thing, they coalesce around the idea that this kind of protocol is either not possible or not desirable. Teachers cite having kids at home, disapproving of too much screen time for kids and feeling uncomfortable with the unequal distribution of digital tools as reasons for their lack of implication.

\section{Discussion}

Different interpretations of pedagogical continuity

With the sudden and unprepared move to distance learning caused by the coronavirus epidemic, certain aspects of the teaching context of French high school mathematics teachers radically changed. This unprecedented situation provided an opportunity to examine the interactions of the constellation of components which contribute to teacher activity, pedagogical choices and thus opportunities for learning, from a new perspective. The results reveal the strong influence of the social component on the cognitive and mediatory components, the destabilising effect on the mediatory component of the institutional demand to move to distance learning and the different interpretations of the term pedagogical continuity which these effects necessitated for individual teachers.

\section{The influence of social situation on pedagogical choices}

The socio-economic situation of the pupils proved pivotal in determining the focus of the pedagogical continuity proposed. This was a major structuring element in the formation of the teacher profiles identified and likely to have a strong impact on learning. The majority of profile 1 teachers, with pupils predominantly from socio-economically advantaged backgrounds, were able to maintain the pace of learning and employ familiar activities. However, the teachers associated with profiles 2 and 3 were obliged to adapt their practices due to the social situation of their students. This had a positive side; "I realise that my pupils are closely accompanied by their parents and so they are lucky to be able to benefit from this period of distance learning", "it's very time-consuming but completely individualised so more beneficial for certain pupils who are lost in the ordinary classroom". However, the situation was deeply frustrating for others, particularly those working with pupils from deprived areas; "[I have] a feeling of being dispossessed from my teaching job", "an exhausting experience with no harmonisation and no preparation". $47 \%$ of the profile 3 teachers completely abandoned the introduction of new knowledge in favour of revision exercises.

\section{Parental implication in learning}

Although widely studied in the literature (Oostdam and Hooge, 2013; Hoover-Dempsey et al., 2002), parental involvement in schools within the context of the French national education system is under-researched. Studies tend to focus on the role of homework in creating social inequalities (Barrère, 2003; Rayou, 2009; Kakpo, 2012). French political and institutional discourse [3] does advocate creating closer links between parents and schools. However, the response from schools has been weak. As a consequence, for most teachers in this study there was little established foundation upon which to build the strong parent-teacher relations required for the effective implementation of a fully distance learning protocol for children and teenagers. Teachers across all profiles ( $86 \%$ of the cohort) were quick to realise the importance of parental implication, and their efforts to forge relationships with parents marks an interesting evolution in the social component of their practice $(76 \%$ signal an

Pedagogical continuity 
JRIT

14,1

86

increase in teacher-parent communication). However, social inequalities are revealed. Profile 1 teachers remark; "the implication of the parents changes the story", "some pupils . . have got down to work and hand everything in regularly. Their parents monitor them closely". However, $48 \%$ of profile 3 teachers state that they cannot rely on the parents to accompany pupils at-home working. There is evidence that this influenced decisions about teaching content; "it's more difficult to explain new notions in the distance learning format, the parents are not teachers and they've got their own work to do" "the distance learning relies too heavily on the resources and the environment of the pupils". Thus, whilst this period provided an opportunity for certain parents to become more directly involved with the school sphere, the unavailability of others and the lack of strong pre-existing parentteacher relationships left the parental role in learning difficult to manage for $64 \%$ of respondents.

\section{The dialogic aspect of learning}

Interaction between the mediatory and cognitive components

As predicted, the transforming effect of teaching through distance learning on the mediatory component proved challenging for many teachers. This affected the cognitive component. This was not true for all participants, particularly those associated with profile 1 . This seems to be linked to an ordinary practice characterised by a reduced focus on dialogic activities. These teachers reported less use of discovery activities and more time devoted to teacher presentation of knowledge than the teachers associated with profiles 2 and 3. Teacher-centred activities lend themselves more easily to direct transferal to a distance learning format without the need for adaptation of the mediatory component. This raises questions concerning the apparent employment of more dialogic teaching methods by those working in schools in less privileged areas. This question is explored in the literature. Chesnais (2018) identify a tendency for teachers in schools in socially deprived areas to focus on problemsolving and procedural knowledge since the language repertoire of the students appears most suited to describing action. In such cases, the teaching practices both fashion and are fashioned by the students in a co-constructive process. The structuring role of the social component within the distance learning protocol is more subtle here. The socio-economic situation of the pupils in the context of the ordinary classroom has already led profile 2 and 3 teachers to explore engaging students in material activities as a way of rendering mathematical knowledge more accessible. Even in ordinary times, these choices, designed to help, may in fact help create inequalities by limiting student opportunities to extrapolate theoretical generalities from material situations (Chesnais, 2014). The problem is compounded by moving to distance learning since the dialogic nature of such activities is complicated to reproduce in the distance format.

\section{The challenge of maintaining dialogic activities}

The difficulties of maintaining space for autonomous learning, discovery approaches and non-routine problems is attested to by $60 \%$ of profile 2 teachers. They pinpoint the difficulties of giving instructions, organising group work, monitoring, correcting, proposing activities involving manipulation of concrete objects and helping weaker students. Different solutions are explored such as reducing the proportion of time devoted to the introduction of new knowledge and providing more individualised teaching. This is particularly marked for the teachers working with students from deprived areas, where attendance in the virtual classroom is poor, and insisting on whole class activities thus appears likely to deepen rather than lesson inequalities between students. The individualisation of teacher-pupil interactions may also be influenced by the strong social role of teachers in schools in 
deprived areas. This is attested to in the open questions; "catastrophic effects for the pupils the furthest removed from the school culture", "a great loss of pupils, about $50 \%$ lost or dropped out". For them, maintaining links with the school, the socio-affective aspect of maintaining pedagogical continuity is a prerequisite to advancing in the curriculum. Across the first three profiles, many teachers collected two or more pieces of homework a week. This marks a change in practice since in the ordinary classroom homework tends to be corrected in class. It can be interpreted as a way of compensating for feelings of disempowerment resulting from the destabilisation of the mediatory component. However, replacing the bidirectional process of correction through discussion with the uni-directional process of correction by the teacher is likely to have a negative effect on learning.

More positively, in certain cases, the opening up of a private channel of communication between teacher and pupils had the unanticipated effect of enhancing engagement in learning. $82 \%$ of profile 2 teachers note that some students, who do not participate in class, are highly invested online. They note "certain pupils, of whom I never would have believed it, are really engaged, are the first to hand in their homework, with friendly messages", "a surprising thing, some pupils, normally reserved, show themselves", "I've had nice surprises, some pupils are really engaged in working from home, even though they do not participate in class when we are at school". Various possibilities of the virtual classroom were also explored as a means of creating new dialogic spaces for learning. Some teachers for whom attendance in the virtual classroom was not constant enough to maintain equality of learning opted for a programme of individualised work with a virtual "class" once a week in which no particular content was proposed, and pupils were free to ask questions about the work done autonomously during the week.

The literature attests to the need to adapt practices when moving from presential to distance teaching because of the non-transferability of certain kinds of task (Horton, 2000), the possible degradation in teacher-pupil communication (Foucault et al., 2002) and the likelihood of an increased workload (Schanck, 2002). However, despite experiencing these complications, many teachers, particularly those associated with profile 2 used the move to distance learning as an opportunity to develop their professional competences through exploration of new tools and methods, some of which they intend to integrate into their ordinary practices. The change of teaching format triggered by the crisis destabilised the normally stable mediatory component of the teaching (Chappet-Pariès et al., 2013; Robert and Hache, 2013) leading to a reorganisation of the cognitive component structured by the social context. Teacher adaptations to the situation open up avenues of reflection for teacher education.

\section{Implications for teacher education \\ Ordinary and distance teaching and learning}

The results attest to the central role of the mediatory component and to the complications which can arise from the destabilisation of this element. This suggests that this component needs to be a focus in teacher education. Robert and Vivier (2013) advocate the use of microobservation, classroom observation and video as tools for engaging teachers with this key aspect of their practice. Incorporating microteaching could also help beginner teachers to practice using language to support and create opportunities for dialogic learning. The results highlight the difficulty of maintaining the dialogic introductory phase in the move to distance learning and the absence of this phase from the ordinary practices of some teachers. This underlines the need within teacher education to continue to explore the role of dialogue in mathematical learning and to support teachers in learning to adapt the mediatory component of their practice to different contexts. Building teacher awareness of the interaction between the different components of their activity would better prepare them for situations which demand adaptations of their practice.

Pedagogical continuity 
JRIT

14,1

88
Faced with the need to adapt to the online context, a relatively high proportion of teachers in this study moved away from dialogic whole class learning towards individualised teaching. For some this choice was to a certain extent an unavoidable consequence of the social situation of the pupils, but others just could not imagine how to maintain dialogic practices within a distance learning format. This does not seem to be related to the technological competences of the teachers but rather to the difficulties of reconfiguring their practice to suit the digital environment; "without debate it is difficult to build new notions", "the lack of interaction between pupils makes me feel uncomfortable setting up introductory activities". Teacher education clearly has a role to play here. Teacher educators need to do more to familiarise teachers with the potential of distance learning tools. Research tends to demonstrate that simply transferring existing practices to distance learning contexts does not permit exploitation of the full potential of digital learning tools. In order to create autonomous learning spaces within a distance learning environment, teachers need to be helped to rethink the tasks they normally employ and the interactions they imply. Asynchronic communication, differentiation of at-home tasks and the virtual classroom as a space devoted to information sharing, argumentation, debate and decontextualisation could all be explored. Enriching pupils' discourse practices (Prediger and Wessel, 2013) could be an interesting starting point for developing new online modes of teacher-pupil and pupil-topupil interactions.

Fully distance learning with its inherent demands for student autonomy is not the ideal protocol for younger learners. However, familiarising teachers and pupils with distance learning tools and their potential uses, and their incorporation into ordinary practices could help to develop pupil autonomy, open new horizons for classroom teaching and provide a foundation for future periods of distance learning.

\section{Teacher education to combat inequalities}

Teacher educators need to address the influence of the underlying social order on teaching and learning. Research continues to explore pupil autonomy within mathematical activity and potential socio-cognitive misunderstandings in teacher-pupil interactions (Bautier and Rochex, 2007; Bonnéry, 2007; Coulange, 2015; Chesnais, 2018). The findings of such studies should be incorporated into teacher education in order to increase teachers' awareness of their possible contribution to maintaining and reducing educational inequalities.

Finally, co-education presents an interesting area of reflection. Whilst some teachers found the new role of parents, during this period testing, others identify it as something they would like to maintain when they return to the classroom. There is a risk that increased levels of co-education might contribute to the social divide. However, co-education means more than simply asking parents to help children with their homework and should be a bi-directional process in which the school sphere welcomes parents and parents contribute to the school life. As such it presents an interesting tool for increasing access to learning for pupils from socially disadvantaged backgrounds by reducing the home-school divide. In order for this to happen in more socio-economically deprived areas, teachers need to be educated to understand their role as representatives of a specific dominant culture. Culturally specific pedagogies are an interesting avenue to explore in this regard (Gay, 2002; Stunell, 2020; Villegas and Lucas, 2002).

\section{Conclusions}

This study explores the complex interplay of teaching context, pedagogical choices, classroom communication and digital tools in the high school mathematics classroom. The results highlight certain elements of teacher activity which could be incorporated into, or 
more fully developed, in the ordinary classroom. This would serve both to improve the quality and equality of maths teaching in French schools and prepare teachers and pupils for a reoccurrence of the distance learning experience should this arise. Areas to explore for researchers and teacher educators alike include the central role of the mediatory component, particularly in maintaining teacher practices influenced by socio-constructivism, the destabilisation of this component within a distance learning format and the interest of increased parental participation in schools. Even those teachers who found the experience enriching remarked on the high level of inequality engendered by the protocol and their interpretation of the term pedagogical continuity largely depended on the social context of their teaching. The unprepared nature of the move to distance learning accentuated the structuring role of social context on pedagogical choices, already identified in scientific studies as an issue which needs to be addressed by researchers, teacher educators and politicians.

\section{Notes}

1. Bilan social du ministère de léducation nationale, de lenseignement supérieur et de la recherche (2015-2016)

2. Responses to the questionnaire were in French and have been translated by the authors.

3. "In order to guarantee success for everybody, school should be constructed with the participation of the parents, whatever their social origin. School will be enriched and consolidated through dialogue and cooperation between all the actors in the educational community." (Code de lÉducation, Article L 111-1, 2019).

\section{References}

Adler, J. (2001), Teaching Mathematics in Multilingual Classrooms, Kluwer Academic Publishers, Dordrecht.

Barrère, A. (2003), Travailler à l'école : que font les éleves et les enseignants du secondaire, Presses universitaires de Rennes, Rennes.

Barwell, R. (2016), "Formal and informal mathematical discourses: Bakhtin and Vygotsky, dialogue and dialectic", Educational Studies in Mathematics, Vol. 92 No. 3, pp. 331-345.

Barwell, R. and Pimm, D. (2016), "Bakhtin and some dilemmas of mathematics - language", in Phakeng, M. and Lerman, S. (Eds), Mathematics Education in a Context of Inequity, Poverty and Language Diversity, pp. 7-18.

Bautier, E. (2006), in Lyon (Ed.), Apprendre à l'école, apprendre l'école : des risques de construction d'inégalités dès la maternelle, de la Chronique sociale.

Bautier, E. and Rochex, J.Y. (1998), L'expérience scolaire des nouveaux lycéens. démocratisation ou massification?, Armand Colin, Paris.

Bautier, E. and Rochex, J.Y. (2007), “Apprendre : des malentendus qui font les différences”, in Terrail, J.D.J.P. (Ed.), Les sociologues, l'école et la transmission des savoirs, La Dispute, Paris, pp. 227-241.

Bonnéry, S. (2007), Comprendre l'échec scolaire. Eleves en difficultés et dispositifs pédagogiques, La Dispute, Paris.

Brousseau, G. (2002), Theory of Didactical Situations in Mathematics, Springer Netherlands.

Chappet-Parriès, M., Robert, A. and Rogalski, J. (2008), "Analyses de séances en classe et stabilité des pratiques d'enseignants de mathématiques expérimentés du second degré”, Educational Studies in Mathematics, Vol. 68, pp. 55-80.

Chappet-Parriès, M., Robert, A. and Rogalski, J. (2013), "Stability of practices: what 8-th and 9-th grade students do with the same teacher during a geometry class period?", in Vandebrouck, F. (Ed.), Mathematics Classrooms, Sense Publishers, Rotterdam. 
JRIT

14,1

Charlot, B., Bautier, E. and Rochex, J.Y. (1992), Ecole et savoir dans les banlieues... et ailleurs, Armand Colin (Formation des enseignants), Paris.

Chesnais, A. (2014), "Différenciation dans le processus d'enseignement-apprentissage en mathématiques en éducation prioritaire et ailleurs", Revue française de pédagogie, Vol. 188, pp. 63-73.

Chesnais, A. (2018), One point of view of French didactics of mathematics on educational inequalities and the role of language in the learning and teaching process (Habilitation à diriger des recherches), Université de Montpellier.

Chevallard, Y. (1999), "L'analyse des pratiques enseignantes en théorie anthropologique du didactique”, Recherches en didactique des mathématiques, Vol. 19 No. 2, pp. 221-266.

Cobb, P. and Bauersfeld, H. (1995), The Emergence of Mathematical Meaning: Interaction in Classroom Cultures, Erlbaum, Hillsdale, New Jerssey, NJ.

Cohen, D. (1998), "Educational technology and school organization", in Nickerson, Raymond, S. and Zodhiates, P. (Eds), Technology in Education: Looking toward 2020, Erlbaum, Hillsdale, New Jerssey, NJ, pp. 231-264.

Coulange, L. (2015), "Quelle visibilité des connaissances et des savoirs ? l'institutionnalisation au coeur de la construction des inégalités scolaires", in et al. (Eds), Rôles et places de la didactique et des didacticiens des mathématiques dans la société et le système éducatif, La Pensée Sauvage, Grenoble, pp. 187-210.

Creswell, J. and Plano-Clark, V. (2007), Designing and Conducting Mixed Methods Research, Sage, Thousand Oaks, California, CA.

Elliot, J. (2005), Using Narrative in Social Research: Qualitative and Quantitative Approaches, Sage, London.

Foucault, B., Metzger, J. and Vaylet, A. (2002), "Les réseaux d'entre aide entre apprenants dans la eformation : nécessité et efficacité ?", Education Permanente, Vol. 152, pp. 95-105.

Fullan, M. (2001), The New Meaning of Educational Change, RoutledgeFalmer, London.

Gay, G. (2002), "Preparing for culturally responsive teaching”, Journal of Teacher Education, Vol. 53 No. 2, pp. 106-116.

Glasersfeld, E. (1991), "An exposition of constructivism: why some like it radical”, in Klir, G.J. (Ed.), Facets of Systems Science, Plenum Press, New York, London, pp. 229-238.

Gordon, M. (2009), "Toward a pragmatic discourse of constructivism: reflections on lessons from practice”, Educational Studies: A Jrnl of The American Educ. Studies Assoc, Vol. 45, pp. 39-58.

Hersant, M. and Perrin, M.J. (2005), "Characterization of an ordinary teaching practice with the help of the theory of didactic situations", Educational Studies in Mathematics, Vol. 59, pp. 113-151.

Horton, W. (2000), Designing Web Based Training, Wiley, New York, NY.

Husson, F., Josse, J. and Pagès, J. (2010), "Principal component methods - hierarchical clustering partitional clustering: why would we need to choose for visualizing data?", Technical Report, Agrocampus.

Kakpo, S. (2012), Les devoirs à la maison : Mobilisation et désorientation des familles populaires, Presses Universitaires de France, Paris.

Kennewell, S., Parkinson, J. and Tanner, H. (2000), Developing the Ict Capable School, RoutledgeFalmer, London.

Kostov, B., Bécue-Bertaut, M. and Husson, F. (2013), "Multiple factor analysis for contingency tables in factominer package", $R$ Journal, Vol. 5, pp. 28-38,

Kozma, R. (2003), Technology, Innovation and Educational Change: A Global Perspective, Information Society for Technology in Education [ISTE] Publications, Eugene, OR.

Krummheuer, G. (1988), “technisierte kommunikation' im kontext kooperativer problem lose prozesse", Technisierte Kommunikation, pp. 43-55. 
Lê, S., Josse, J. and Husson, F. (2008), "Factominer: an r package for multivariate analysis", Journal of Statistical Software, Vol. 25 No. 1, pp. 1-18.

Mullis, I. and Martin, M. (2106), About Timms 2015. Timms Pirls International Study Center, Lynch School of Education, Boston College and International Association for the Evaluation of Educational Achievement (IEA).

OCDE (2019), PISA, Editions OCDE, Paris, Résultats du pisa 2018 (volume i) : Savoirs et savoir-faire des élèves.

Oostdam, R. and Hooge, E. (2013), "Making the difference with active parenting, formating educational partnerships between parents and schools", Eur J Psychol Educ, Vol. 28, pp. 337-351.

Pimm, D. (2004), Discourse Analysis and Mathematics Education: An Anniversary of Sorts, Paper Presented at the ICME-10 Conference, Danemark, Copenhagen, pp. July 4-10.

Planas, N., Morgan, C. and Schütte, M. (2018), "Mathematics education and language: lessons and directions from two decades of research", in Dreyfus, T., Artigue, M., Potari, D., Prediger, S. and Ruthven, K. (Eds), Developing Research in Mathematics Education. Twenty Years of Communication, Cooperation and Collaboration in Europe, Routledge, New York, NY, pp. 196-210.

Prediger, S. and Wessel, L. (2013), "Fostering German language learners' constructions of meanings of fractions - design and effects of a language - and mathematics - integrated intervention", Mathematics Education Research Journal, Vol. 25 No. 3, pp. 435-456.

Rayou, P. (2009), Faire ses devoirs: Enjeux cognitifs et sociaux d'une pratique ordinaire, Presses universitaires de Rennes, Rennes.

Robert, A. (2001), "Les recherches sur les pratiques des enseignants et les contraintes de l'exercice du métier d'enseignant", Recherches en didactique des mathématiques, Vol. 21 No. 1.2, pp. 57-80.

Robert, A. and Hache, C. (2013), "Why and how to understand what is at stake in a mathematics class”, in Vandebrouck, F. (Ed.), Mathematics Classrooms, Sense Publishers, Rotterdam.

Robert, A. and Rogalski, J. (2002), "Le système complexe et cohérent des pratiques des enseignants de mathématiques: une double approche", Canadian Journal of Science, Mathematics and Technology Education, Vol. 2 No. 4, pp. 505-528.

Robert, A. and Vivier, L. (2013), "Analyser des vidéos sur les pratiques des enseignants du second degré en mathématiques: des utilisations contrastées en recherche en didactique et en formation de formateurs - quelle transposition?", Education et didactique, Vol. 7 No. 2, pp. 115-144.

Salomon, G. (1990), “The computer lab: a bad idea now sanctified”, Educational Technology, Vol. 30 No. 10 , pp. $50-52$.

Schanck, R. (2002), Designing World Class E-Learning, McGraw- Hill, New York, NY.

Simon, M. (1995), "Reconstructing mathematics pedagogy from a constructivist perspective", Journal for Research in Mathematics Education, Vol. 26 No. 2, pp. 114-145.

Stamou, A. and Chronaki, A. (2007), Writing mathematics through dominant discourses: the case of a greek school mathematics magazine, in Pitta-Pantazi, D. and Philippou, G. (Eds), Proceedings of the 5th Conference of the European Society for Research in Mathematics Education, pp. 1311-1320.

Steffe, L.P. (1991), “The constructivist teaching experiment: illustrations and implications", Radical Constructivism in Mathematics Education, Vol. 177, p. 194.

Stunell, K. (2020), "Supporting student-teachers in the multicultural classroom", European Journal of Teacher Education. doi: 10.1080/02619768.2020.1758660.

Tashakkori, A. and Teddlie, C. (2003), in Tashakkori, A. and Teddlie, C. (Eds), The Past and Future of Mixed Methods Research: From Data Triangulation to Mixed Model Designs, Sage, Thousand Oaks, California, CA.

Pedagogical continuity 
Thurston, D., Penner, A. and Penner, E. (2017), "Categorical inequality: schools as sorting machines”, Annual Review of Sociology, No. 43, pp. 311-330.

Villegas, A. and Lucas, T. (2002), "Preparing culturally responsive teachers: rethinking the curriculum", Journal of Teacher Education, Vol. 53 No. 1, pp. 20-32.

Voigt, J. (1994), "Negotiation of mathematical meaning and learning mathematics", Educational Studies in Mathematics, Vol. 26 Nos 2-3, pp. 275-298.

Windschitl, M. (2002), "Framing constructivism in practice as the negotiation of dilemmas: an analysis of the conceptual, pedagogical, cultural, and political challenges facing teachers", Review of Educational Research, Vol. 72 No. 2, pp. 131-175.

\section{Further reading}

Earle, R. (2002), "The integration of instructional technology into public education: promises and challenges”, ET Magazine, Vol. 42 No. 1, pp. 5-13.

Serdyukov, P. (2017), "Innovation in education: what works, what doesn't, and what to do about it?", Journal of Research in Innovation Teaching and Learning, Vol. 10 No. 1, pp. 4-33.

Zimmerman, J. (2006), "Why some teachers resist change and what principals can do about it", National Association of Secondary School Principals, Vol. 90 No. 3, pp. 238-249.

\section{Corresponding author}

Grégory Train can be contacted at: gregory.train@u-bordeaux.fr

For instructions on how to order reprints of this article, please visit our website: 